\title{
O MANÁ DO DESERTO? A “CABRA NOSSA DE CADA DIA” FOI O CAMINHO DE SUPERAR A DOR E PARTILHAR O AMOR
}

\author{
THE MANNA OF THE DESERT? THE "GOAT OF OUR EVERY DAY" WAS THE WAY TO \\ OVERCOME PAIN AND SHARE LOVE
}
Recebido em 19.01.2020 Aprovado em 10.03.2020
Avaliado pelo sistema double blind review
DOI: https://doi.org/10.32888/cge.v8i1.40439

\begin{abstract}
Antônia Márcia Rodrigues Sousa
pesquisadoramarciarodrigues@gmail.com

Programa de Pós-Graduação em Estudos Fronteiriços/Universidade Federal de Mato Grosso do Sul (UFMS)

https://orcid.org/0000-0003-0659-9897.
\end{abstract}

\section{Ruan Carlos dos Santos}

ruansantos1984@hotmail.com

Programa de Graduação e Tecnologia em Gestão Financeira/Centro Universitário UNIAVAN

Aluno Especial no Doutorado em Administração/UNIVALI

https://orcid.org/0000-0003-0659-9897

\author{
Alcineide Aguiar Pimenta \\ pimentaalcideide@gmail.com \\ Programa de Graduação em Administração/ Faculdade Luciano Feijão \\ Doutoranda em Desenvolvimento Sustentável / UNIVATES \\ https://orcid.org/0000-0001-7880-1017
}

\section{Resumo}

Este caso para ensino apresenta a história de um projeto social chamado "A Cabra Nossa de Cada Dia" criado em 1993 pelo religioso Padre João Batista Frota, em Sobral-Ceará com o propósito de minimizar a fome e automaticamente combater a desnutrição e mortalidade infantil. Tornou-se mundialmente conhecido por sua capacidade de criação de fortes laços sociais que imprimiram compartilhamento e transferência de conhecimento capaz de mudar o cenário social e econômico de mais de 700 famílias em 17 comunidades atendidas. Os fatos comprobatórios do projeto foram coletados por meio de informações em livros, artigos, relatório técnico e entrevistas como o fundador e os coordenadores locais das comunidades assistidas. O caso apresenta distintas ramificações teóricas e práticas, entretanto a abordagem difundida tem viabilidade para os Cursos de graduação e Pós-graduação Lato Sensu em Administração e áreas afins. Especificamente a narrativa possibilita discussões nas disciplinas de Estratégia Empresarial no conteúdo de Capacidade Absortiva e no Terceiro Setor na disciplina de Inovação Social.

Palavras-chave: Projeto social. Compartilhamento. Transferência de conhecimento. Comunidades.

\begin{abstract}
This teaching case presents the story of a social project called "A Cabra Nossa de Cada Dia" created in 1993 by the religious Father João Batista Frota, in Sobral-Ceará with the purpose of minimizing hunger and automatically combating child malnutrition and mortality. It has become known worldwide for its ability to create strong social ties that have led to knowledge sharing and transfer capable of changing the social and economic scenario of more than 700 families in 17 communities served. The supporting facts of the project were collected through information in books, articles, technical reports and interviews with the founder and local coordinators of the assisted communities. The case has different theoretical and practical ramifications, however the widespread approach is viable for undergraduate and graduate courses in Administration and related fields. Specifically, the narrative allows discussions in the disciplines of Business Strategy in the content of Absorptive Capacity and in the Third Sector in the discipline of Social Innovation.
\end{abstract}

Keywords: Project Social. Sharing. Knowledge transfer. Communities. 


\section{O PRELÚDIO}

O caboclo cearense das matas secas do sertão desperta por mais um dia e encontra a mesma situação, sol, vento e seca, afinal estamos falando do mês de julho de 1993, período em que a situação de penúria e de fome acometeu muitas famílias da zona rural do município de Sobral, cidade a $220 \mathrm{~km}$ de Fortaleza, capital do Ceará. Essa tal situação de infortúnio provocada pela seca já permeava a vida de muitas famílias desde 1989, sendo que, em 1993 , quando a pobreza e a miséria se alastraram em grande parte da zona norte do Estado do Ceará, especificamente, em algumas comunidades com distâncias medianas da sede do município.

Os impactos econômicos e sociais que acometiam aquelas famílias eram acompanhados pelo gestor público que buscava, por meio de ações paliativas, como entrega de cestas básicas e carros pipas para fornecimento de água, reduzir a evolução da ação predatória da seca que agia de forma avassaladora na vida daquelas pessoas, transmitindo uma imagem desoladora para a humanidade.

Ainda assim, o cenário homem, natureza e o poder público não apresentavam uma integração visível, e as ameaças à vida tornaram-se evidentes levando o homem do campo ao desespero ao assistir de forma impotente a desnutrição tomar conta das crianças e idosos em consonância com outras doenças provocadas pela falta de alimentos e de higiene, elevando consideravelmente a mortalidade e o êxodo rural.

Nessa atmosfera de perdas sociais e afetivas incitadas pela privação de recursos, a comunidade se utiliza dos apelos à fé como a última condição para sobreviver ao caos instalado e pede socorro ao Pai celestial representado na ambiência terrestre pelos religiosos. Assim, surge a oportunidade da comunidade discutir tal situação com uma das paróquias da cidade de Sobral, com o apoio da Empresa Brasileira de Pesquisa Agropecuária EMBRAPA-Caprinos

Vale ressaltar que a religiosidade católica está no berço da cultura da cidade por uma série de artefatos, dentre eles o reconhecimento da existência de aproximadamente 30 igrejas que acolhem seus fiéis de sol a sol como afirma "o caboclo do sertão".

Tais características tornaram-se primordiais para ouvir o clamor do caboclo pedindo pela vida das crianças e dos idosos uma alternativa de sobrevivência em meio ao caos social instalado naquelas comunidades. E logo ao conhecer os pormenores da precariedade vivida por aquelas famílias, não demorou a identificar mecanismos que de forma sustentável tornassem a vida daquela população menos desafortunadas.

E com uma velocidade inédita, em 20 de julho de 1993, mobilizou sua equipe e demais representantes das comunidades e criaram a primeira Assembleia da Comunidade de Base realizada na paróquia em busca de encontrar uma solução condizente com as palavras de Jesus: "Eu vim para que todos tenham vida e a tenham em abundância" (BÍBLIA JERUSALÉM, Jo cap. 10, ver. 10).

E com esses ensinamentos deixados por Jesus e disseminados pelo Padre João Batista, imediatamente iniciou-se um trabalho com a comunidade mediado pela paróquia na perspectiva de encontrar alternativas concretas e duradouras para criar um novo cenário para aquelas famílias.

Então, com base nos aspectos geográficos da região delineada pela caatinga e no clamor social vigente, algumas sugestões foram identificadas pela comunidade, entretanto, a maioria era de cunho assistencialista capaz de solucionar problemas imediatos.

Dotado de uma visão abrangente, o Padre João Batista, em comunhão com sua equipe, associou algumas das alternativas da comunidade à desigualdade social instalada e aos recursos naturais disponíveis. Mesmo diante de algumas divergências, lançou a estratégia de criação de um projeto que criassem cabras leiteiras, pelo valor nutricional do leite, amplamente conhecido no meio científico por sua capacidade de alimentar especialmente crianças e pessoas idosas, situação condizente com o cotidiano daquelas pessoas.

$\mathrm{Na}$ verdade, apesar da rápida adesão à ideia, logo surgiu uma série de questionamentos que necessitavam com urgência de uma solução. Desse modo, novamente os moradores acolheram a ideia de buscar parceiros que contribuíssem nos mais distintos aspectos. E logo o auxílio técnico, administrativo e gerencial ficou disponível para a comunidade. 
Então o passo seguinte era mostrar para a comunidade que o projeto não fazia parte de um instrumento assistencialista, e que iria exigir muito empenho e compromisso de todos para que fosse efetivado. Inicialmente observou-se um alto grau de resistência por parte de alguns membros da comunidade. Afinal, por anos foram acostumados com ações paliativas de assistencialismos.

Como qualquer instituição, o projeto precisava de um nome que apresentasse uma imagem positiva no âmbito social que atraísse a formação de alianças e parceiras para potencializar financeiramente a implantação da ideia.

Com essa premissa, iniciou-se o processo de criação de uma nomenclatura para o projeto, após várias sugestões, um técnico da Embrapa, propôs o nome "Cabra Nossa de Cada de Dia", que imediatamente foi aprovado por todos. Sendo formalizado em referência e alusão ao "Pai Nosso", em que se expressa a sentença "o pão nosso de cada dia", que remete à vida através do leite que mata a fome do sertanejo.

O projeto Cabra Nossa Cada Dia acabara de nascer, mas para uma gestão eficiente necessitava de capitalização para iniciar suas atividades.

\section{A PEDRA ANGULAR}

Não foi simples definir as estratégias de operacionalização para atender às famílias diante do quadro alarmante de necessidades básicas. Então, após avaliação dos coordenadores da comunidade, ficou definido o repasse de uma cabra fêmea "prenhe" para as famílias identificadas com crianças pequenas.

A formalização da entrega ocorreu por meio da assinatura de um termo de compromisso pela família com o Projeto. Em uma das cláusulas, ficou determinado que, em um período de dois anos, a família beneficiada deveria entregar ao Projeto pelo menos duas crias fêmeas para que houvesse o repasse a outra família carente.

Em face de tudo isso, o prelúdio dessa história tem sua pedra angular na comunidade de São Joaquim, que, em 1993, quando foi construído o primeiro aprisco com capacidade para 150 animais, com recursos advindos das parcerias e do trabalho conjunto da comunidade que viu os primeiros resultados dos seus esforços e desafios sendo concretizados.

Nessa etapa, as familias já estavam cientes da metodologia utilizada para escolha dos beneficiários seminais, no caso seria a família com criança em fase infantil. Desde o início, ficou estabelecido que cada família receberia uma cabra prenhe, com a finalidade de, em curto espaço de tempo, ter a disponibilidade do leite para melhoria na alimentação das crianças e dos idosos.

Enquanto isso o destino dos novos animais era definido de acordo com o sexo, os cabritos machos as famílias poderiam capitalizar da forma como considerassem viável a sua sobrevivência, alguns optavam por abater, outras conservavam, e a maioria vendia para comprar outros produtos de necessidades diária. Enquanto as fêmeas, por duas crias consecutivas após apartadas, eram entregues ao projeto para beneficiar novas famílias.

Com a finalização do repasse das animais fêmeas, as famílias tornavam-se proprietárias da cabra matriz e das suas reproduções futuras. Após esse processo, estimava-se que 80\% das famílias apresentavam profundas mudanças econômicas e sociais no seu cotidiano familiar.

Os primeiros cincos anos do projeto de 1993 a 1998 com o atendimento a 10 comunidades, iniciadas pela São Joaquim, São Francisco, São Domingo Boqueirão, Baracho, Jordão, Croatá, Santo Hilário, Santo Antônio, Baixa Grande, Fazenda Diamantina e Desterro, foram marcados por uma série de ajustes nos processos gerenciais e na adaptação da comunidade, bem como o ingresso de novas comunidades.

É considerável afirmar que a coordenação do projeto, sistematicamente, visita as comunidades em período trimestral para avaliação geral dos animais e controle dos repasses e da prospecção de novos integrantes ao projeto. Esse momento também é marcado por apresentação de compromissos individuais com o projeto e as exposições de interesses coletivos como a alimentação das crianças, o acompanhamento dos idosos, a orientação dos jovens por meio de temáticas sobre educação e saúde. 
No âmbito gerencial, o crescimento do projeto possibilitou criar um encontro anual das lideranças com a coordenação geral, com o intuito de socializar, integrar, avaliar as ações desenvolvidas e projetar a adoção de novas atividades para o ano seguinte.

A eficiência gerencial dos primeiros cinco anos apresentou uma sustentabilidade para as mudanças ocorridas nos anos de 1998 a 2004, como a construção de um poço profundo na comunidade de Ipueirinha possibilitando o plantio de pastagem para alimentação dos animais, suporte para a irrigação das hortas e manutenção da "farmácia viva", que é umas ações criativas da comunidade advindas dos processos de orientação profissional e de apoio alternativo saúde.

No período de 2004 a 2008, ocorreu uma expressiva dinâmica técnica e gerencial com a troca do rebanho por cabras de raças com maior potencial leiteiro, alto índice de lactação, excelente qualidade de fertilização e de fácil adaptação ao solo nordestino.

Outros avanços ocorridos nesse período foram a implantação de luz elétrica em algumas comunidades, calçamento, casas de alvenaria, água encanada em algumas comunidades. Observa-se a formação de uma organização produtiva que altera a renda das famílias com os pequenos rebanhos domésticos. E como forma de controle dos animais, os pequenos proprietários recebem treinamento para gerenciar seu novo negócio, já que os animais têm que apresentar uma identificação de direito de propriedade. Importante ressaltar que havia alguns pequenos produtores na comunidade de Santo Hilário que possuíam um rebanho de até 32 animais. Esse crescimento também é perceptível no compartilhamento de informações por meio da troca de experiências exitosas em relação a criação do rebanho, o gerenciamento dos pequenos negócios que foram se formando ao longo do tempo.

A difusão da cultura dos saberes locais vai sendo disseminadas e logo se percebe outras mudanças de hábitos e comportamentos, como é caso da comunidade de Jaíbaras, em relação a conscientização ambiental advinda da preservação e do uso correto do reservatório, já que se trata de uma das comunidades que abriga um dos maiores reservatórios de água do Ceará, o açude Aires de Souza. O aproveitamento dessa água se deu com a criação de peixes em gaiola, ação implantada pelo mutirão comunitário.

Na perspectiva intangível, segundo o discurso de alguns membros da comunidade, cresceu o respeito nas relações parentais, a autoestima feminina e o reconhecimento do público externo: "Já nos últimos tempos nós recebemos visitas de muita gente da capital e até do outro lado do mundo". Essa fala de um dos membros da comunidade é uma referência a muitos visitantes, pesquisadores de distintas instituições de ensino brasileira e algumas visitas realizadas pelos amigos alemães que fizeram as doações iniciais para implantação do projeto.

\section{O COMPARTILHAMENTO}

Um projeto, uma realidade e um fato, não havia condições financeiras para iniciar as atividades. Outro estágio se iniciara, é o momento de encontrar antídoto para a situação vigente. E assim como nenhum desafio é intransponível aos olhos da fé e da crença, Padre João Batista olha para a paisagem cinzenta da seca em contraste ao crepúsculo do entardecer e ao ouvir tinir do sino acredita ser um bom presságio para as ideias noturnas.

E é na alvorada do dia seguinte que a boa notícia é veiculada aos integrantes do projeto. No silêncio da noite, entre uma Ave-Maria e outra, um anjo protetor sussurra em seu ouvido, fazendo-lhe lembrar que do outro lado do oceano existia, entre as belezas arquitetônicas, uns anjos terrestres prontos a colaborar.

E assim em uma linguagem caracteristicamente cearense, Padre João Batista Frota contou a alguns amigos alemães o que se passava por aqui com o seu povo e quais propostas tinham de solução que não se efetivara por falta de recursos financeiros. Assim em um piscar de olho, por ordem celestial, o problema foi elucidado por meio da ação transformadora das redes de relacionamento criada no seminário, antes chamada de "para todas as horas".

E com ajuda do Graham Bell, uma mensagem foi repassada aos amigos da Alemanha. E sem querer mais detalhes, a situação criou forma com a ajuda dos europeus que financiaram sem fins lucrativos as primeiras 50 cabeças de cabras de raças para inicialmente formar o rebanho. 
A realização do projeto Cabra Nossa de Cada Dia é pautado nos direcionamentos do provérbio "fazer o bem sem olhar a quem". Com essa máxima, o Padre João Batista Frota, ao longo dos anos, foi formando grandes parcerias que se tornaram responsáveis pela grandeza social do projeto nos mais diversos quesitos técnicos, gerenciais e financeiros.

Observa-se que dentre suas distintas ações sociais, é possível valorar o grau de qualidade de vida das pessoas, o fortalecimento dos laços sociais das comunidades, o crescimento das relações sociais que de maneira geral, implicam na formação de uma cultura de busca de conhecimento coletivo adquirido por meio de capacitação e de transferência de conhecimento e inovação transmitido pelos parceiros.

Estes avanços sociais e organizacionais advindos das parcerias são percebidos por meio das novas técnicas de produção de queijos e doces de leite de cabra, conscientização política da comunidade e aplicação de técnicas gerenciais na organização produtiva e disseminação de boas práticas de gestão, ambos são resultados da geração de conhecimentos e identificação de novas ideias que são potencializadas pelas instituições parceiras como a EMBRAPA-Caprinos, com sua expertise oportuniza desde o início, a capacitação técnica nos mais diversos estágios que vai desde o processo de inseminação artificial ao melhoramento genético do rebanho.

A Universidade Estadual Vale do Acaraú-UVA, por meio do curso de Zootecnia, proporciona apoio técnico à produção correta do leite com fins à fabricação de queijo e doce de leite de cabra. A Secretaria de Agricultura do Estado do Ceará-SEAGRI participou da doação de mais 100 cabras mestiças que foram distribuídas entre as 17 comunidades. A Prefeitura Municipal de Sobral, por meio da Secretaria de Agricultura e Pecuária apoia a manutenção de hortas, sítios, apicultura e piscicultura. O Rotary Club Forchheim da Alemanha ajudou financeiramente na construção de abrigos para os animais, cacimbas e plantação de capim em treze comunidades. O Serviço de Apoio às Pequenas e Médias Empresas -SEBRAE apoia a capacitação dos jovens com metodologias voltadas para o apoio ao desenvolvimento local e ao empreendedorismo.

Outros agentes públicos como o Departamento Nacional de Obras contra as Secas - DNOCS atuou como parceiro com a doação de 60 hectares de terra para pastagens dos animais e construção de sítios em duas comunidades. O Departamento Nacional de Transito - DETRAN apoia com a doação de caprinos e ovinos apreendidos em operações oficiais.

Na iniciativa privada o apoio da Pastoral da Criança da Paróquia do Patrocínio é fundamental com o repasse de treinamento para as famílias sobre alimentação saudável para as crianças e cuidados básicos com a saúde. Ainda é possível contar com a participação de outras instituições privadas como Big pneus, Sobral Gráfica, Augusto Azevedo Engenharia, Moageira Serra Grande e Instituto de Estudos e Pesquisas do Vale do Acaraú-IVA, o apoio dessas instituições vem por meio de por meio de recursos financeiros, suporte logístico e operacional.

Para as famílias, a participação dessas instituições é mais que é uma parceria, é uma aliança de compromisso que vai se tornando mais firme a medida que os conhecimentos vão se transformando em realidade. É o que acontece com a participação do SEBRAE na comunidade com a criação de pequenos negócios como: salão de beleza, loja de materiais e miudezas, comércio de cereais. Ainda é possível perceber o crescimento do poder de compra, especialmente em relação a alimentos básicos e a material escolar.

Os conhecimentos repassados transformaram-se em ações que fortaleceram a vida de muitas famílias por meio da criação de novos negócios que oportunizaram alguns jovens a se tornarem agentes chave do seu desenvolvimento.

Tal autonomia de algumas comunidades leva o fundador a algumas indagações em relação ao seu total desligamento do projeto que atualmente tem sua participação somente como colaborador social, porém, sua imagem ainda é muito forte em relação a ao projeto.

É notório que a integração de conhecimento empírico e formal repassados pelo fundador e por essas instituições parceiras modificou o cotidiano das comunidades. Sendo assim, será que essa troca de conhecimentos internos e externos são considerados capazes de romper com as adversidades gerenciais externas e manter o projeto em operação sem os vínculos sociais do seu fundador e das instituições parceiras? 


\section{O APOGEU}

Rompendo as barreiras com um crescimento e reconhecimento incomparável, o projeto segue com a manutenção das ações realizadas e com a prospecção de novas estratégias sociais em realização desde a década de 2008 ao alvorecer de 2018.

Em referência aos anos anteriores, o Projeto "Cabra Nossa de Cada Dia" oportunizou às comunidades atendidas não apenas o alimento que sacia a fome, mas incentivou as famílias e os jovens através de capacitações, discussões temáticas em palestras e reuniões o estímulo à criação de pequenos negócios a partir das potencialidades locais, a promoção do desenvolvimento ecosocioambiental nas comunidades, contribuindo diretamente para a melhoria da qualidade de vida e consequentemente resgatando a autoestima, a cidadania, o revigoramento da fé, o senso de justiça e a solidariedade entre as famílias e os seus pares.

O reconhecimento dessas mudanças excedeu as instâncias municipais e estaduais no ano de 2008 quando o projeto foi agraciado com o Prêmio Betinho: Atitude Cidadã, que valoriza aqueles que se mobilizam com o intuito de melhorar as condições de vida de comunidades em situação de vulnerabilidade.

Tal agraciamento impulsionou ainda mais a continuidade das ações e a implantação de melhorias no projeto, como tratamento de dessalinização de água, criação de um sítio que tem sua produção de frutas, legumes e hortaliças vendidas para comércios locais, produção de queijos e doce de leite de cabra. A operacionalização dessas ações, oportunizaram a algumas famílias a tornarem-se autossustentáveis. Atualmente muitas participam do projeto como parceiras, enquanto outras gerenciam pequenos negócios advindos do projeto.

Em 2011 novamente o projeto teve um notório reconhecimento nacional com a entrega do Prêmio de Direitos Humanos, pela presidente da República Dilma Rousseff ao Padre João Batista Frota, que foi agraciado na categoria de enfrentamento à pobreza.

As condecorações deram continuidades em 2012 com o recebimento de uma placa como um dos projetos finalista do Prêmio ODM Brasil - Objetivos de Desenvolvimento do Milênio Brasil, na categoria erradicação da pobreza, concedido pela Secretaria Geral da Presidência da República.

Nesse percurso, os indicadores são de mais de 700 famílias atendidas em 17 comunidades, perfazendo um total de aproximadamente mais de 1000 crianças assistidas, com idade entre zero e dez anos.

$\mathrm{Na}$ última década, ganhou destaque com o reconhecimento nacional do prêmio Atitude Cidadã em 2008 e, em 2011, recebeu da Presidência da República o Prêmio Nacional dos Direitos Humanos.

O ano de 2012 também foi marcado por uma nova etapa, com a transição de projeto Cabra Nossa de Cada Dia para uma instituição jurídica denominada de Associação Cabra Nossa de Cada Dia. Essa decisão consensual entre o fundador e os membros gerenciais resultou no desligamento do Padre João Batista Frota, que passou a atuar na associação como conselheiro informal, captação de novos parceiros, voluntário financeiro e mediador dos recursos enviados pelos seus amigos alemães que contribuem do período inicial da ideia até os dias atuais.

De modo geral, a visão de Padre João Batista Frota é de que as comunidades se tornem autossustentáveis permitindo que a associação mantenedora receba dos parceiros apenas alguns suportes técnicos-gerenciais. Esse processo já vem sendo trabalhado de modo experiencial com a tendência que as maiores fontes de recursos sejam oriundas das parcerias privadas.

Em 2013, recebeu o prêmio Nacional de Inovação em Saúde Pública, desta vez pela Medical Services de Inovação em Saúde Pública da SANOFI Indústria Farmacêutica, por suas contribuições sociais voltadas para a melhoria da saúde pública.

Essas projeções instigaram a comunidade a criar novos projetos como construções de casas de mutirões e incentivo à formação de novos projetos de apicultura, piscicultura e criação de galinha caipira, em comunidades circunvizinhas.

A gestão da associação atualmente é realizada por uma equipe gerencial com cargos inerentes às suas exigências jurídicas e pelo trabalho contínuo e voluntário dos Coordenadores Locais. Em 2016, com o apoio dos parceiros e 
a contribuição do "dízimo", a associação inaugurou nova sede, no centro da cidade de Sobral, com as bênçãos de seu criador.

Ao longo dessas duas décadas e meia, é notável a eficiência de muitos processos técnicos e gerenciais. Observa-se que as necessidades básicas iniciais foram substituídas por anseios estruturais de melhor acesso às comunidades por meio de estradas pavimentadas, água potável, já que a estiagem ainda continua assolando o Nordeste, dificultando a manutenção dos reservatórios de água para consumo humano, dos animais e das plantas, como os sítios de frutas e hortaliças e a farmácia viva.

Em relação ao consumo inicial do leite, a sua atividade fim atualmente é praticamente para uso medicinal e de doações para outras comunidades que ainda necessitam para suprir alimentação de crianças e idosos. A independência econômica e social das famílias nas 17 comunidades atendidas torna-se cada vez mais recorrente. A comunidade São Domingos apresenta o maior índice desenvolvimento socioeconômico. Atualmente está com um projeto de comercialização industrial de leite de cabra em fase de implantação, também é conhecida por abrigar o maior número de pesquisadores e acadêmicos das mais distintas instituições de ensino superior do país, com projetos em fase de experimento. Essa fase tem oportunizado ao questionamento, será que a transferência e a combinação dos conhecimentos prévios com os novos conhecimentos técnicos, gerenciais e sociais adquiridos com as experiências das comunidades fortalecem as rotinas internas permitindo a continuidade do projeto sem o apoio os fortes laços sociais do fundador? Para o coordenador geral, Jorge Luís de Paula, atualmente o projeto alcança cada comunidade de forma única: "Procuramos atuar com estratégias para o desenvolvimento rural sustentável dentro de uma linha do perfil de cada comunidade e estabelecemos estratégias diante das forças e fraquezas.

\section{NOTAS DE ENSINO}

\section{OBJETIVOS EDUCACIONAIS DO CASO}

O caso "Aprender e compartilhar, não importa se começa pelo amor ou pela dor", tem por objetivo oportunizar os alunos e profissionais da área de Administração, áreas afins e de Cursos de Pós-graduação Lato Sensu uma discussão em relação ao processo de aprendizagem e compartilhamento na perspectiva do ambiente interno e externo.

\section{UTILIZAÇÃO RECOMENDADA}

O caso apresenta uma história permeada por descobertas de potencialidades locais e rede de relações foi desenvolvido para ser utilizado em cursos de graduação em disciplinas relacionadas a estratégias organizacionais e terceiro setor, além de poder ser utilizado em cursos de pós-graduação latu senso em Inovação social e estratégias organizacionais.

\section{FONTE DE OBTENÇÃO DOS DADOS DO CASO}

Os dados primários foram coletados por meio de entrevistas com fundador, Padre João Batista Frota, o coordenador geral do projeto e os coordenadores locais das comunidades atendidas. Os dados primários foram integrados aos dados secundários obtidos por meio de revistas, artigos científicos e relato técnico, livros.

\section{DINÂMICA E AGENDA PARA DISCUSSÃO DO CASO}

A operacionalização dessa etapa, deve ocorrer por meio de um planejamento antecipado da leitura do caso e das sugestões apresentadas para suporte teórico. Orienta que o caso seja trabalhado ao longo de uma aula de, no mínimo, em uma aula de uma hora e cinquenta minutos de duração. Para isso, o tabela 1 sugere um planejamento sumarizado para viabilizar as discussões. 
Tabela 1. Planejamento das discussões

\begin{tabular}{|c|l|}
\hline Duração & \multicolumn{1}{c|}{ Atividades } \\
\hline $15 \mathrm{~min}$ & $\begin{array}{l}\text { Apresentação geral do caso com seus pressupostos teóricos e a formação dos grupos } \\
\text { para as discussões. }\end{array}$ \\
\hline $30 \mathrm{~min}$ & $\begin{array}{l}\text { Contextualização do caso com a exposição dos objetivos propostos. Apresentação dos } \\
\text { questionamentos com as respectivas proposições teóricas. }\end{array}$ \\
\hline $30 \mathrm{~min}$ & Apresentação, discussão e alinhamento teórico com as respostas dos grupos. \\
\hline $15 \mathrm{~min}$ & Considerações finais com o fechamento do caso. \\
\hline \multicolumn{2}{|c|}{ Fonte: Elaborado pelos autores (2018). }
\end{tabular}

\section{QUESTÕES PARA DISCUSSÕES}

1. É possível afirmar que a aquisição de conhecimento adquirido em consonância com o trabalho em grupo e a intenção de aplica-lo de forma comercial e estratégica garante o gerenciamento do projeto frente as variações do ambiente? Justifique.

2. Tomando como base os estudos acerca da divisão teórica de capacidade absortiva de Zahra e George (2002), é possível afirmar que a troca de conhecimentos advindos da trajetória da comunidade com os parceiros promove uma capacidade absortiva potencial? Justifique.

3. Seguindo as orientações teóricas de Zhara e George (2002), é possível afirmar que o reconhecimento nacional do projeto está relacionado com a capacidade absortiva realizada da comunidade? Justifique.

4. Quais as evidências reais que este caso apresenta Inovação Social?

5. Baseado em Murray et. al., (2010) identifique no caso em qual estágio de inovação social encontra-se o projeto?

\section{ANÁLISE DO CASO}

\section{Capacidade Absortiva}

A expressão capacidade absortiva vêm dos estudos de Cohen e Levinthal (1989; 1990), como a capacidade da empresa identificar, assimilar, explorar, valorar o conhecimento e aplicá-los para fins de mercado. Ainda segundo os autores, a similaridade dos conhecimentos adquiridos anteriormente e posteriormente quando associados, apresentam maior efetividade no processo de absorção tornando o ambiente mais competitivo.

Nas últimas décadas a capacidade absortiva desponta como um dos principais construtos sobre gestão (Daspit \& Souza, 2013; Flatten et al., 2011; Jimenez-Castillo \& Sanchez-Perez, 2013); trabalho em grupo (Filenga, 2014); inovação (Murovec \& Prodan, 2009; Liao et al.,2011); aprendizado organizacional (Zahra \& Hayton, 2008); alianças estratégicas (Balbinoto Marques, 2009); transferência do conhecimento (Schreiber et al., 2011; Castro, 2013).

Como um dos componentes das capacidades dinâmicas da organização (Teece, Pisano \& Sheun, 1997; Wang \& Ahmed, 2007), a capacidade absortiva apresenta uma abordagem multidisciplinar, que tem como o propósito de articular e implantar mudanças organizacionais por meio do conhecimento existente e compartilhado dentro da organização.

Zahra e George (2002, p. 186) a capacidade absortiva pode ser compreendida como "um conjunto de rotinas e processos organizacionais pelos quais as firmas adquirem, assimilam, transformam e exploram conhecimento para produzir uma capacitação dinâmica". Ainda segundo os autores a integração das capacidades no seio organizacional criam uma sustentação competitiva capaz de alcançar superioridade em relação ao seu desempenho.

Varsiani et. al. (2010) defendem que quanto maior o nível de educação e treinamento dos colaboradores, mais aptos eles se tornam em assimilar e transformar o novo conhecimento.

Ao alinhar o conceito inicial de Cohen e Levinthal $(1989,1990)$ com a ideia de Zhara e George (2002) compreendese que a absorção e a utilização do conhecimento no cotidiano organizacional quando explorado e compartilhado de forma estratégica faz com que a empresa gere e mantenha vantagem competitiva sustentáveis. 
A visão inicial acerca da capacidade absortiva Cohen e Levinthal $(1989,1990)$ é representada por quatro componentes composto pela Aquisição, Assimilação, Transformação e Exploração que integrados estão divididos na capacidade absortiva potencial e capacidade absortiva realizada (Zhara \& George 2002; Fosfuri \& Tribo, 2008).

Compreende-se que na capacidade absortiva potencial a assimilação e a aquisição aumentam a propensão da organização em adquirir e assimilar uma diversidade de novos conhecimentos externos que possam ser utilizados em posteriores situações provocadas por uma conjuntura ambiental (Zhara \& George 2002; Melkas \& Harmaakorpi, 2008).

A capacidade absortiva realizada objetiva entender como a transformação e exploração do conhecimento externo previamente adquirido estão sendo capitalizado em prol de inovação que proporcione vantagem competitiva em curto ou médio prazo (Zhara \& George 2002; Leal-Rodriguez et al., 2014).

A relação entre capacidade absortiva potencial e realizada apresenta uma tendência de conhecimentos orientados ao futuro da organização, seja por meio da potencialização dos resultados dos conhecimentos existentes ou pela busca de distintos e inovadores conhecimentos.

\section{Inovação Social}

A temática Inovação Social vem tomando proporções relevantes nas esferas acadêmica, governamental e empresarial, devido a crescente demanda da sociedade por soluções práticas para os problemas sociais de forma mais efetiva (João, 2014). Segundo Mulgan, Tucker, Ali e Sanders (2007) a inovação social se refere a produtos e serviços inovadores que se propõe a satisfazer uma necessidade social, ou seja, o principal intuito não é obter vantagem competitiva e sim gerar um valor social. Assim, percebe-se que desenvolvimento da inovação social busca minimizar e/ou solucionar problemas sociais onde nem o poder público e nem a iniciativa privada atuaram de maneira satisfatória.

Para Bignetti (2011, p. 2), a inovação social pode ser definida como o "resultado do conhecimento aplicado as necessidades sociais através da participação e da cooperação de todos os atores envolvidos, gerando soluções novas e duradouras para grupos sociais, comunidades ou para a sociedade em geral".

Segundo Cloutier (2003), pesquisadora do Centre de Recherche sur les Innovations Sociales (CRISES), no Canadá, a inovação é uma resposta nova para uma situação social considerada insatisfatória, que busca o bem-estar dos indivíduos e das comunidades, ressaltando a participação dos atores, durante todo o processo e o efeito dessa inovação social. De acordo com Moulaert et al. (2005) a inovação social é caracterizada por atender às necessidades humanas não satisfeitas, por aumentar os direitos de acesso aos cidadãos e por melhorar as capacidades humanas. Essa perspectiva considera os resultados que a inovação social pode gerar.

Rodrigues (2007) considera a inovação como uma nova forma de fazer as coisas, a partir da interação entre diferentes atores e experiências. Amplia o conceito, no que diz respeito à interação entre diferentes atores e a possibilidade de cada indivíduo assumir novos papéis, a partir da troca de experiência e de desenvolvimento pessoal.

Segundo Maimon (2015), pode-se identificar pelo menos duas grandes abordagens. A primeira está interessada em soluções para os principais problemas sociais, com base em iniciativas privadas de organizações com fim lucrativo (empresas) ou sem fim lucrativo (ONGs). A segunda abordagem coloca maior ênfase na natureza coletiva dos processos e produtos de inovação social. Nesta perspectiva as inovações são degraus que levam à mudança da rede social, ou seja, a transformação das relações sociais que estão na origem do problema de coesão social.

Murray et. al., (2010) propõem alguns estágios no desenvolvimento das inovações sociais, conforme figura 1, disponibilizando uma estrutura para a reflexão sobre os diferentes tipos de suporte que inovadores e inovações necessitam para crescer. Estes estágios consistem em: (1) Inspiração; (2) Propostas e ideias; (3) Protótipos e pilotos; (4) Sustentação; (5) Dimensionamento e difusão; (6) mudança sistêmica. (MAIMON, et. al., 2015). 
Figura 1. Estágios de Inovação Social

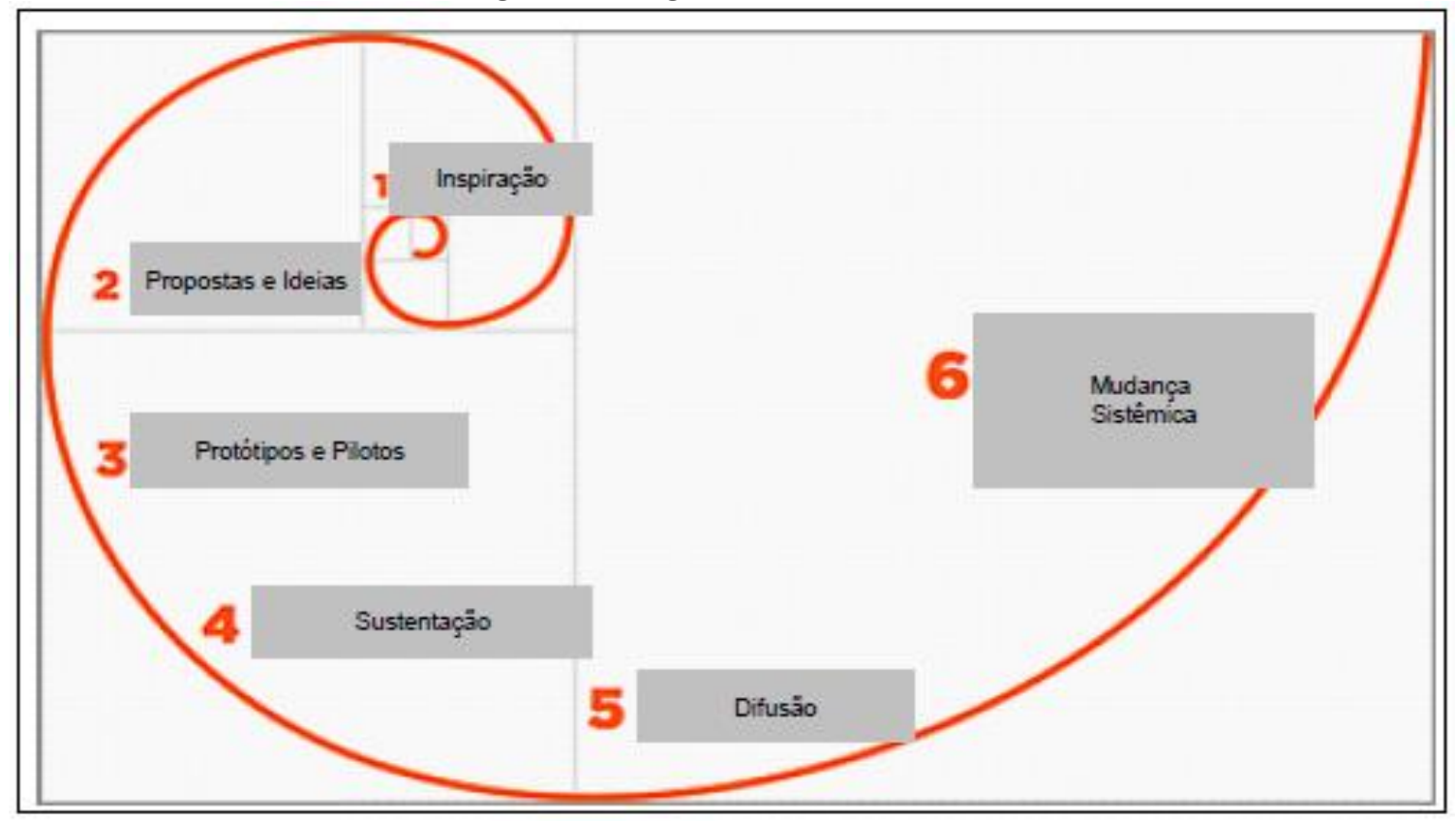

Fonte: Murray, Caulier-Grice e Mulgan, (2010, p. 11)

O primeiro estágio se refere à percepção de um problema, uma carência ou uma incapacidade do setor público ou privado de dar respostas através dos meios de ação tradicionais. Neste estágio, deve-se atentar para as raízes do problema, não apenas seus sintomas mais visíveis. O segundo estágio está associado à criação de ideias, valendose da criatividade para abrir novos caminhos na solução de problemas. O terceiro estágio envolve o desenvolvimento de protótipos e pilotos, com a intenção de testar as ideias na prática. Refere-se ao aprendizado pela prática onde podem ser redefinidos novos caminhos. O quarto estágio implica a sustentação econômica de longo prazo, incluindo a criação de orçamentos e alocação de recursos. O quinto estágio (dimensionamento e difusão) está associado à ampliação da ação ou difusão para uma área maior de abrangência e, por fim, o sexto estágio, refere-se à mudança sistêmica, considerada o objetivo final de uma inovação social, que implica em uma mudança permanente e sustentável.

$\mathrm{Na}$ visão dos autores, estas etapas não são sempre sequenciais, podendo haver feedback e interação entre elas. Murray et al., (2010) propõem que o desenvolvimento da inovação social pode ser impulsionado a partir destes estágios, os quais devem impactar nas mudanças sustentáveis. Percebe-se, assim, que a multiplicidade e amplitude das abordagens teóricas conferem às inovações sociais uma complexidade que vai além de suas definições conceituais, permeando também as interações entre os atores sociais envolvidos na promoção de transformações sociais duradouras.

\section{Referências}

BIGNETTI, L. P. As inovações sociais: uma incursão por ideias, tendências e focos de pesquisa. Ciências Sociais Unisinos, v. 47, n. 1, 2011.

COHEN, W. M.; LEVINTHAL, D. A. Absorptive capacity: a new perspective on learning and innovation. Administrative Science Quarterly, v.35, n.1, p. 128-152, 1990.

CLOUTIER, J. Qu'est-ce que l'innovation sociale? In: CRISES. Centre de Recherche Sur Les Innovations Sociales. Cahiers du CRISES. Québec, 2003.

DASPIT, J.; SOUZA, D. E. Understanding the multi-dimensional nature of absorptive capacity. Journal of Managerial Issues, v.25, n3, p. 299, 2013.

FLATTEN, T. C.; ENGELEN, A.; ZAHRA, S. A.; BRETTEL, M. A measure of absorptive capacity: Scale development and validation. European Management Journal, v.29, n.2, p. 98- 116, 2011. 
FOSFURI, A.; TRIBÓ, J. A. Exploring the antecedents of potential absorptive capacity and its impact on innovation performance. Omega, v. 36, p.173-187, 2008.

FREITAS, H.; MARTENS, C. D. P.; BOISSIN, J.; BEHR, A. Elementos para guiar ações visando à orientação empreendedora em organizações de software. Revista de Administração, v. 47, n. 2, p. 163-179, 2012.

JIMENEZ-CASTILLO, D; SANCHEZ-PEREZ, M. Market knowledge absorptive capacity: a measurement scale. Information Research Journal, v.18, n.4, 2013.

JOÃO, I. S. Modelo de gestão da inovação social para empresas sociais. Tese de Doutorado. Programa de Pós-graduação da Universidade de São Paulo - USP, São Paulo, Brasil, 2014.

KREISER, P.; MARINO, L.; WEAVER, M. Assessing the psychometric properties of the entrepreneurial orientation scale: A multi-country analysis. Entrepreneurship Theory and Practice, v. 26, n. 4, p. 71-95, 2002.

LEAL-RODRÍGUEZ A. L.; ROLDÁN J. L.; ARIZA-MONTES J. A.; LEAL-MILLÁN A. From potential absorptive capacity to innovation outcomes in project teams: the conditional mediating role of the realized absorptive capacity in a relational learning context. Int J Project Management, v.32, n. 6, p: 894-907, 2014.

LIAO, J.; WELSCH, H.; STOICA, M. Organizational absorptive capacity and responsiveness: an empirical investigation of growth-oriented SMEs. Entrepreneurship Theory and practice, v. 28, n. 1, p. 63-85, 2003.

LIN, Z.; YANG, H.; DEMIRKAN, I. The performance consequences of ambidexterity in strategic alliance formations: empirical investigation and computational theorizing. Management Science, v. 10, n. 5, p. 1645-1658, 2007.

LUBATKIN, M. H.; SIMSEK, Z.; LING, Y.; VEIGA, J. F. Ambidexterity and performance in smallto-mediumsized firms: the pivotal role of top management team behavioral integration. Journal of Management, v.32, n.5, p. 646-672, 2006.

LUMPKIN, G. T.; DESS, G. G. Linking two dimensions of entrepreneurial orientation to firm performance: the moderating role of environment and industry life cycle. Journal of Business Venturing, vol. 16, p.429-451, 2001.

MARCH, J. Exploration e Exploitation in Organizational Learning. Organizational Science, v. 2. n. 1, p. 71-87, 1991.

MAVONDO, F. T.; CHIMHANZI, J.; STEWART, J. Learning orientation and market orientation: relationship with innovation, human resource practices and performance. European Journal of Marketing, v. 39, n. 11/12, p. 1235-1263, 2005.

MAIMON, D. C.; C. AFONSO, R. Economia Criativa enquanto tecnologia social: um estudo de Caso da favela da mangueira, Rio de Janeiro. Porto Alegre: ALTEC, 2015.

MOULAERT, F.; NUSSBAUMER, J. Defining the social economy and its governance at the neighbourhood level: A methodological reflection. Urban Studies, v. 42, n. 11, p. 2071-2088, 2005.

MULGAN, G.; TUCKER, S.; ALI, R.; SANDERS, B. Social innovation: what it is, why it matters and how it can be accelerated. London: The Young Foundation, 2007.

MURRAY, R.; CAULIER-GRICE, J.; MULGAN, G. The open book of social innovation. London: National Endowment for Science, Technology and the Art : Young Foundation, 2010.

MUROVEC, N.; PRODAN, I. Absorptive capacity, its determinants and influence on innovation output: crosscultural validation of the structural model. Technovation, v.29, n.12, p.859-872, 2009.

O'REILLY, C. A.; TUSHMAN, M. L. Organizational Ambidexterity: Past, Present, and Future. The Academy of Management Perspectives, v. 27, n. 4, p. 324-338, 2013.

RAISCH, S.; BIRKINSHAW, J.; PROBST, G.; TUSHMAN, M. L. Organizational ambidexterity: balancing exploitation and exploration for sustained performance. Organization Science, v.20, n.4, p.685-695, 2009.

ROSA, A. C.; RUFFONI, JAbsorptive capacity of firms that interact with university. IAMOT, 2013.

RODRIGUES, A. L. Modelos de gestão e inovação social em organizações sem fins lucrativos: divergências e convergências entre Nonprofit Sector e Economia Social. Organizações \& Sociedade, v. 14, n. 43, p. 111-128, 2007. 
ROTHAERMEL, F. T.; ALEXANDRE, M. T. Ambidexterity in technology sourcing: The moderating role of absorptive capacity. Organization Science, Chicago, v. 20, n.4, p. 759-780, 2009.

SANTOS, F. H. R.; FINGER, A. B. Capacidade absortiva: um olhar sobre a produção científica brasileira. In: Encontro da Associação Nacional de Pesquisa e Pós-Graduação em Administração (ENANPAD), 39, 2015, Belo Horizonte, Brasil.

SILVEIRA-MARTINS, E., ROSSETO, C. R., \& AÑAÑA, E. S. Ambidestria, exploração ou explotação e seus efeitos no desempenho organizacional de vinícolas brasileiras. Revista em Agronegócios e Meio Ambiente, Maringá, v. 7, n. 3, p. 707-732, 2014.

TALEBI, K.; TAJEDDIN, M. The adoption of new and innovative knowledge by small and medium enterprises of Iran: Opportunities and constraints for growth. African Journal of Business Management, v. 5, n. 1, p. 39 49, 2011.

TEECE, D. Dynamic Capabilities: A Guide for Managers. Ivey Business Journal, v. 04, p. 32-40, 2011.

TEECE, D. J.; PISANO, G.; SHUEN, A. Dynamic Capabilities and Strategic Management. Strategic Management Journal, p. 509-533, 1997.

TEECE, D. J. Explicating Dynamic Capabilities: the Nature and Microfoundations of (sustainable) Enterprise Performance. Strategic Management Journal, v. 28, n. 13, p. 1319-1350, 2007.

WEICK, K.; WESTLEY, F. Aprendizagem organizacional: confirmando um oxímoro. In: CLEGG, S. R.; HARDY, C.; NORD, W. (orgs.). Handbook de Estudos Organizacionais. São Paulo: Atlas, v.3, p. 361 - 388, 2004.

ZAHRA, S. A.; HAYTON, J. C. The effect of international venturing on firm performance: The moderating influence of absorptive capacity. Journal of Business Venturing, v. 23, n. 2, p. 195-220, 2008.

ZAHRA, S. A.; GEORGE, G. Absortive capacity: a review, reconceptualization, and extension. Academy of Management Review, v. 27, n.2, p.185-203, 2002.

ZAHRA, S. A.; FILATOTCHEV, I.; WRIGHT, M. How do threshold firms sustain corporate entrepreneurship? The role of boards and absorptive capacity. Journal of Business Venturing, v.24, p. 248-260, 2009. 